\title{
Superlatives and concerns in osteopathic medical education
}

This issue of the JAOA identifies a number of superlatives in osteopathic medical education. You will read that the profession has set records in the following areas:

- The 1991-1992 entering class had more applicants than any class in history, with 4,163 participants in the American Association of Colleges of Osteopathic Medicine Application Service (AACOMAS).

- Enrollment in the osteopathic medical colleges is at a record high, with 1,950 enrolled in the 1990 entering class.

- More female osteopathic medical students are enrolled than ever before in history. Likewise, women account for a higher percentage of osteopathic medical students (32.7\%) than ever before.

- Interns are attracted by new "specialty internships" and "special emphasis internships," which allow concentration in a specialty while meeting $\mathrm{AOA}$ intern training requirements. In 1991-1992, a total of 171 interns enrolled in such specialty programs.

- More residents are enrolled in osteopathic medical training programs than ever before, with an $11.2 \%$ gain in the number of residents training in osteopathic medical institutions during 1991-1992.

- Osteopathic residency programs in emergency medicine showed a dramatic $50 \%$ gain, and several other specialties showed encouraging gains in residency enrollment.

- The AOA Bureau of Research has created and funded a new "Clinical Investigator Development Award." This award is intended to support selected DOs preparing for careers as clinical investigators.

However, not all is good news. The data presented in this issue of the JAOA also offer the following warnings about the future of osteopathic medical education:
- The number of residents in osteopathic general practice programs shows a $10 \%$ decline.

- The decline continues in the number of residents training in pediatrics programs in osteopathic medical institutions. A total of three pediatrics residents are enrolled in all osteopathic medical institutions in the current year, compared with 27 residents enrolled in 1988-1989.

- The number of osteopathic physicians choosing allopathic residency programs continues to increase, with a $17.3 \%$ increase in the number of DOs in allopathic residency programs in 1990-1991. During 1990-1991, 65\% of DOs in residency training were in allopathic programs. In contrast with the declining enrollment in osteopathic residency programs in family practice and pediatrics, enrollment continued to increase in allopathic residency programs in these specialties.

- The number of osteopathic residents in allopathic programs who are seeking AOA approval of their training declined, down from 406 for residents in training in 1990-1991 to 323 residents training during 1991-1992.

- In spite of enthusiasm for specialty internships and an ample number of open positions, osteopathic internships showed no significant overall gain in the number of graduates taking osteopathic internships. Similarly, no increase occurred in the proportion of graduates taking osteopathic internships. In 1991-1992, only $76 \%$ of the funded intern positions were filled.

- Graduate medical education opportunities are still clustered in a few states. In 1991$1992,76 \%$ of the filled positions occur in only seven states. Few opportunities exist in the Southern or Western states, in spite of vigorous program development activities.

What do the next 10 years hold? This dec- 
ade will be the "make-or-break" period for osteopathic graduate medical education. Survival of osteopathic intern and residency training programs-and with that, to some extent, the survival of osteopathic hospitals-will depend on the profession's ability to:

$\square$ Recruit students oriented toward osteopathic medicine and reinforce osteopathic medical values during undergraduate medical education.

- Develop and consistently apply quality standards in graduate medical education.

- Redesign programs within these standards that meet the educational and personal needs of trainees.

$\square$ Place renewed emphasis on "the osteopathic advantage" to offer potential trainees a real difference in the nature of their education.

This issue of the JAOA presents more than just statistical information; it presents a challenge to the profession in determining the future of osteopathic medical education.

HELEN H. BAKER, PhD

Associate Director

AOA Department of Education
. . . Special Contonnial gume 1892-1992 . . . .

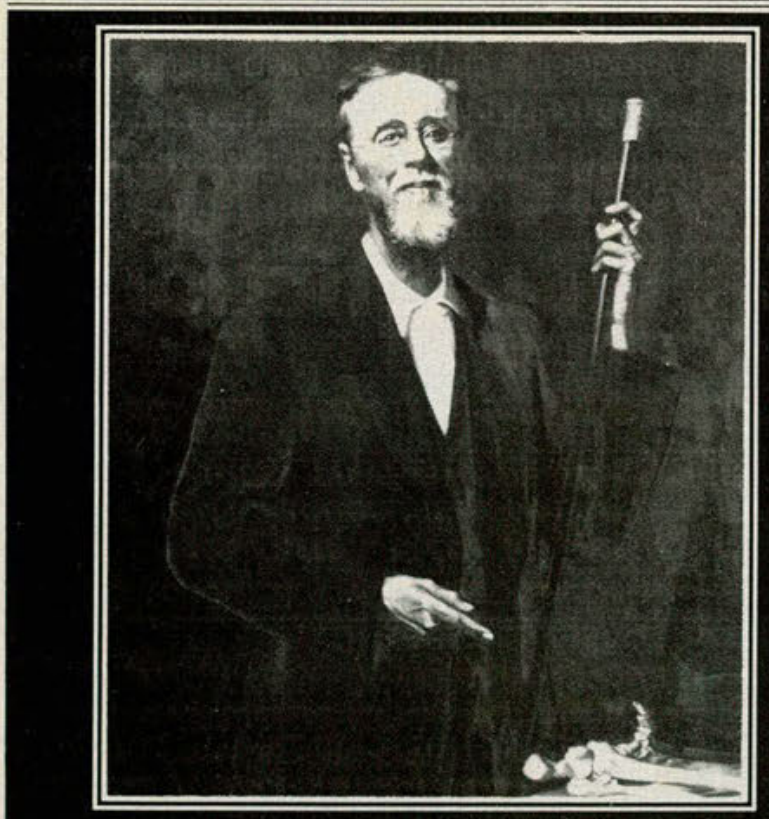

Still National Osteopathic Museum 1992 CAIENDAR
Still National Osteopathic Museum Special Centennial Issue 1992 Calendar

Featuring People, Places And Things of Significant Historical Interest To The Profession

Start the new year with pride by reviewing some of the great moments in osteopathic history.

Give a unique gift that's certain to be appreciated all year long by members and friends of the profession.

ORDER NOW - Available 1st of October, 1991.

Name:

Address:

Unit Price $\$ 7.00$

Quantity

Include \$1.50 each for Postage and IIandling

Total Enclosed \$

Please return check or money order to:

Still National Osteopathic Muscum

311 South Fourth Street

Kirksville, Missouri 63501 


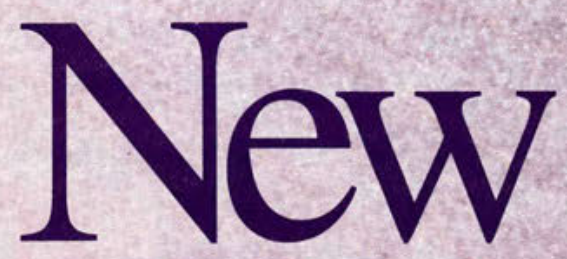

FROM MERCK SHARP \& DOHME

\section{For mild-to-moderate hypertension}

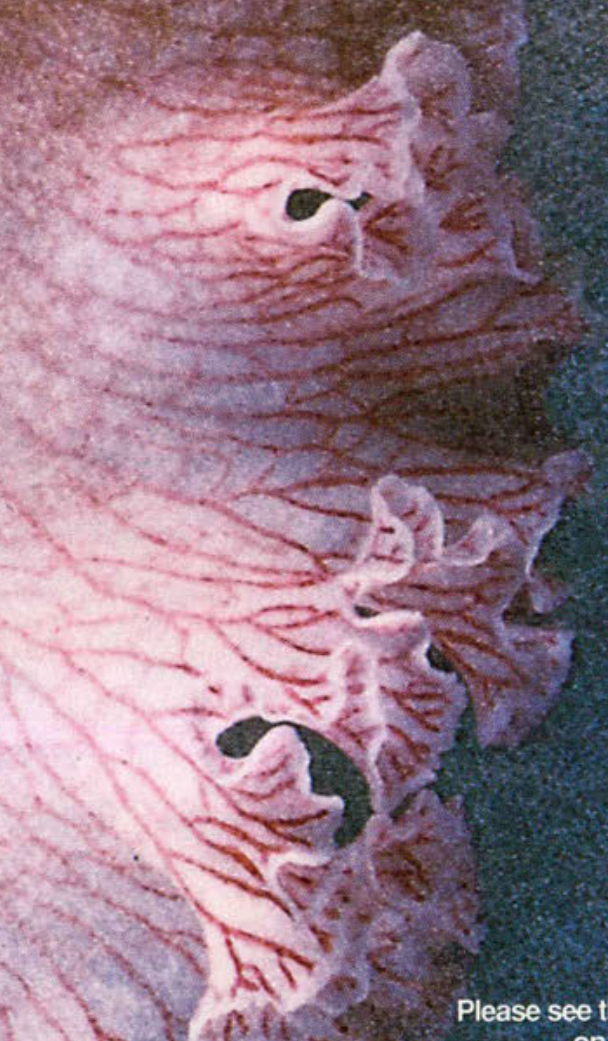

Please see the Brief Summary of Prescribing Information on the last page of this advertisement. 
From the Astra/Merck Research Programs
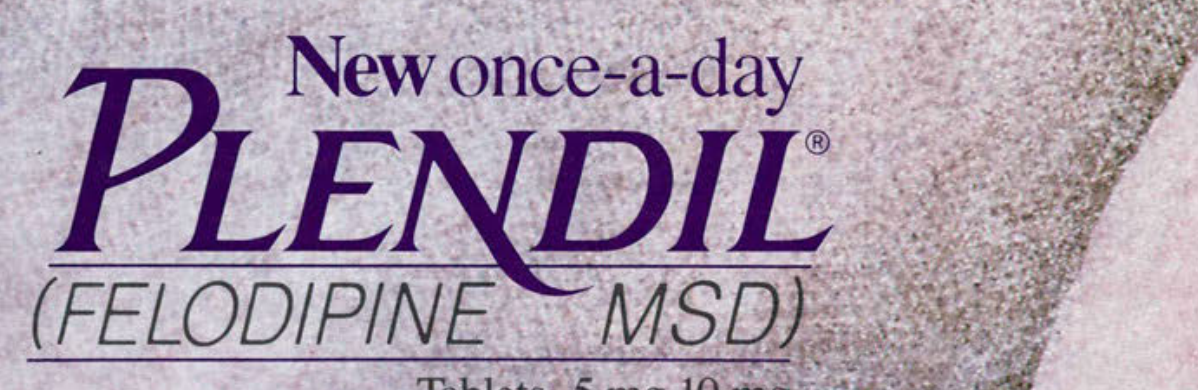

Tablets, $5 \mathrm{mg} 10 \mathrm{mg}$ 


\title{
A calcium channel blocker that provides
}

\author{
- once-a-day dosing \\ - vascular selectivity
}

- savings from $23 \%$ to $60 \%$ compared with the starting doses of other once-a-day calcium channel blockers ${ }^{*}$

*Based on the usual recommended starting dose(s) from the manufacturers' current product information for once-a-day calcium channel blockers for hypertension. Prices are manufacturers' direct prices, if available, or average wholesale prices from Medi-Span : Prescription Pricing Guide, August 1991, based on the most frequently purchased package size for each strength. 


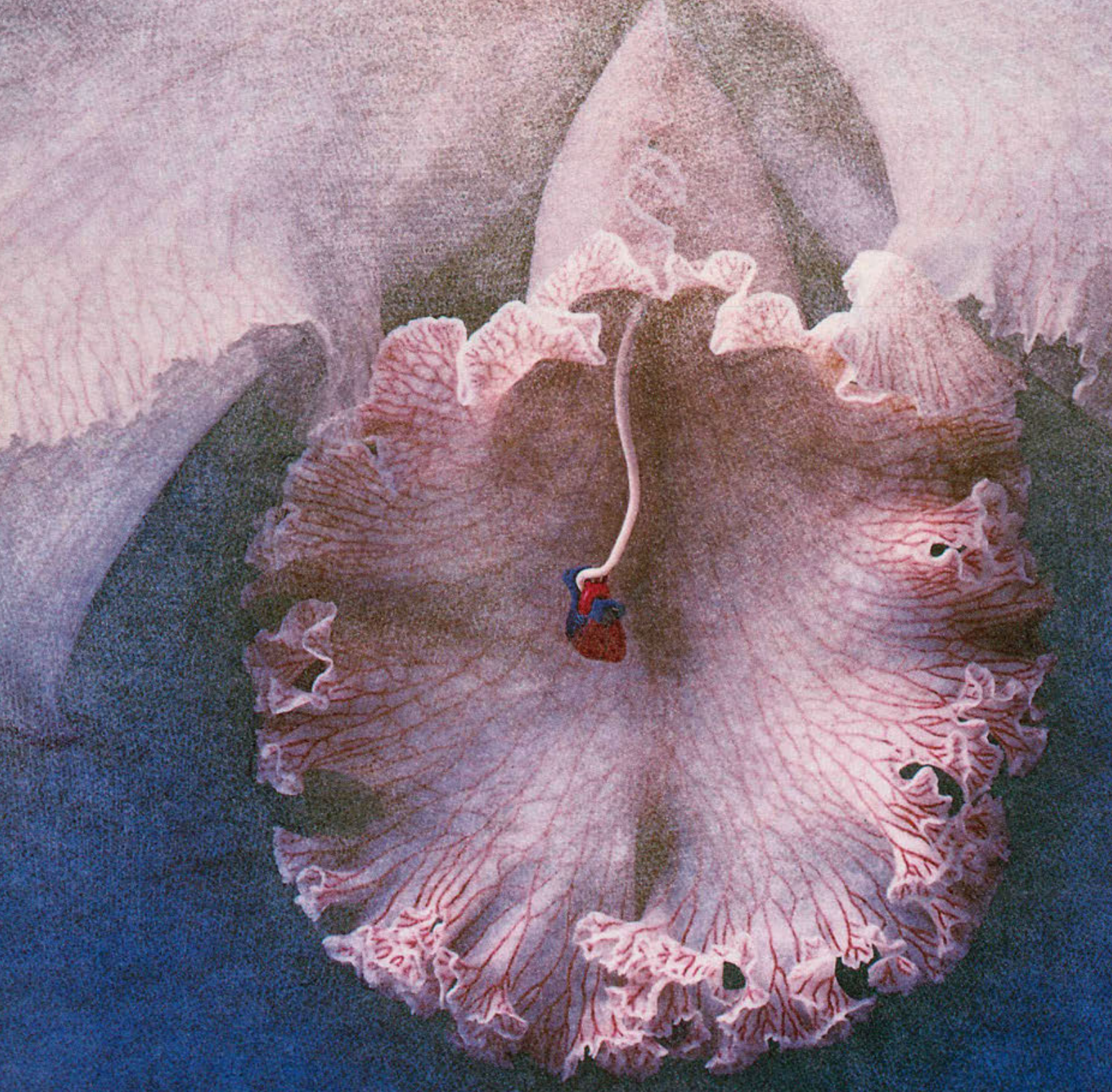




\section{Vascular selective}

\section{PLENDIL focuses more activity on vascular smooth muscle than cardiac muscle}

- The effect of felodipine on blood pressure is principally a consequence of a dose-related decrease of peripheral vascular resistance in man with a modest reflex increase in heart rate

- In vitro studies show that the effects of felodipine on contractile processes are selective, with greater effects on vascular smooth muscle than cardiac muscle

PLENDIL is contraindicated in patients who are hypersensitive to this product. Felodipine, like other calcium antagonists, may occasionally precipitate significant hypotension and, rarely, syncope. It may lead to reflex tachycardia, which in susceptible individuals may precipitate angina pectoris. (See ADVERSE REACTIONS.)

Patients over 65 years of age or patients with impaired liver function may have elevated plasma concentrations of felodipine and may therefore respond to lower doses of PLENDIL. These patients should have their blood pressure monitored closely during dosage adjustment of PLENDIL and should rarely require doses above $10 \mathrm{mg}$. (See DOSAGE AND ADMINISTRATION.)

Please see the Brief Summary of Prescribing Information on the last page of this advertisement.

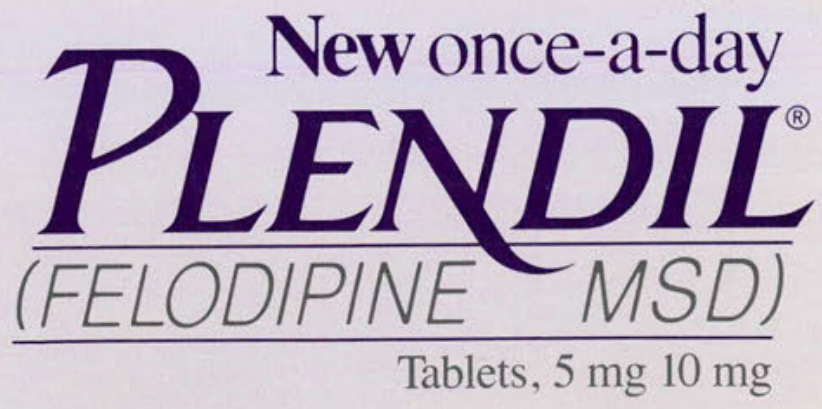


$\operatorname{lin} 20$

$\sin (x)=0$

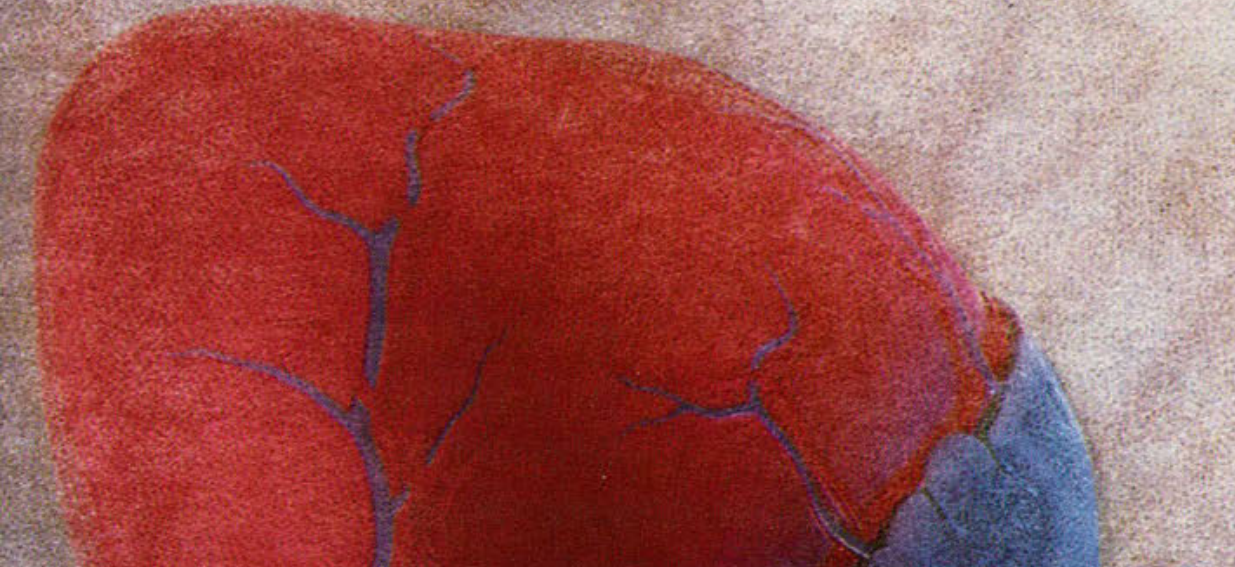

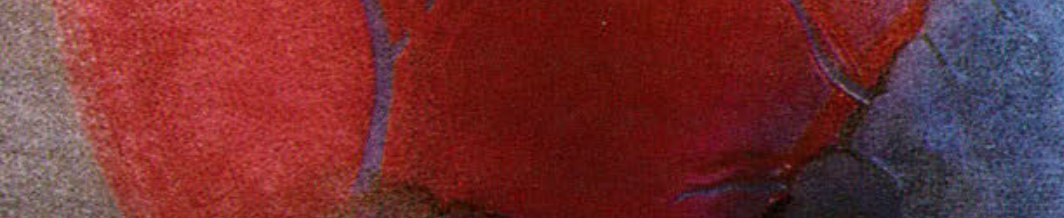

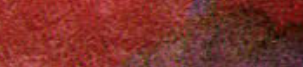

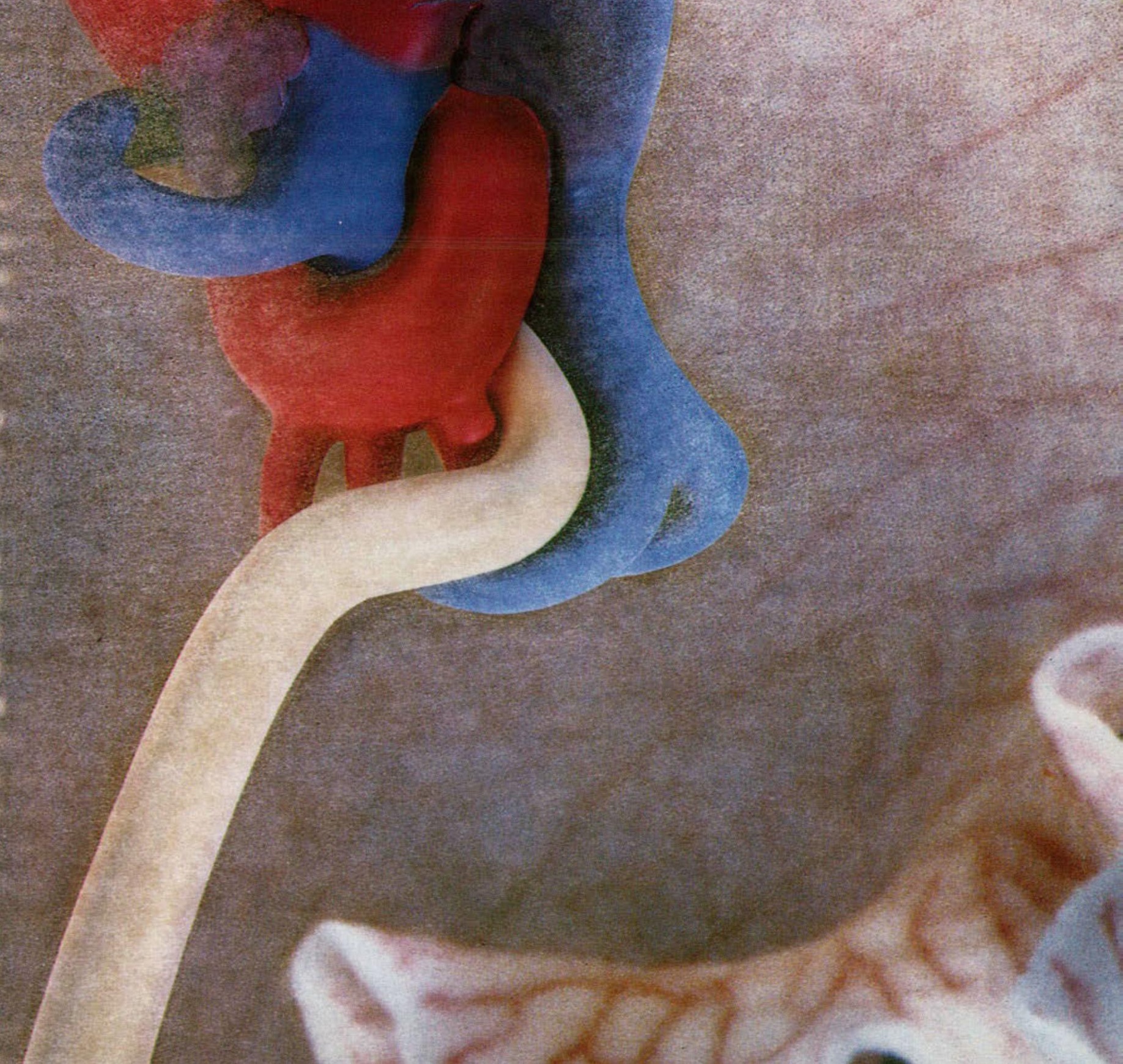




\section{Favorable}

\section{hemodynamic profile}

\section{PLENDIL:}

- Had no significant effect on cardiac conductivity (PR, PQ, and HV intervals)

- Renal vascular resistance is decreased by felodipine while glomerular filtration rate remains unchanged

In clinical studies:

\begin{tabular}{|lcccc|}
\hline $\begin{array}{l}\text { Peripheral } \\
\text { resistance }\end{array}$ & $\begin{array}{c}\text { Blood } \\
\text { pressure }\end{array}$ & $\begin{array}{c}\text { Cardiac } \\
\text { conductivity }\end{array}$ & $\begin{array}{c}\text { Glomerular } \\
\text { filtration rate }\end{array}$ & $\begin{array}{c}\text { Cardiac } \\
\text { output }\end{array}$ \\
\hline Decreased & $\begin{array}{c}\text { Substantial } \\
24-\text { hour } \\
\text { control }\end{array}$ & $\begin{array}{c}\text { No } \\
\text { significant } \\
\text { effect }\end{array}$ & Unchanged & $\begin{array}{c}\text { No } \\
\text { effect }\end{array}$ \\
& $\begin{array}{c}\text { demonstrated } \\
\text { demong }\end{array}$ \\
\hline
\end{tabular}

A reflex increase in heart rate frequently occurs during the first week of therapy; this increase attenuates over time. Heart rate increases of 5-10 beats per minute may be seen during chronic dosing. The increase is inhibited by beta-blocking agents.

${ }^{*}$ In clinical trials in hypertensive patients without clinical evidence of left ventricular dysfunction, no symptoms suggestive of a negative inotropic effect were noted; however, none would be expected in this population

Although acute hemodynamic studies in a small number of patients with NYHA Class II or III heart failure treated with felodipine have not demonstrated negative inotropic effects, safety in patients with heart failure has not been established. Caution, therefore, should be exercised when using PLENDIL in patients with heart failure or compromised ventricular function, particularly in combination with a beta blocker.

- Generally well tolerated in clinical trials at the usual dosage range

The most common clinical adverse experiences reported with PLENDIL administered as monotherapy in all settings and with all dosage forms of felodipine were peripheral edema and headache. Peripheral edema was generally mild, and it was age and dose related and resulted in discontinuation of therapy in about 4 percent of the enrolled patients. Discontinuation of therapy due to any clinical adverse experience occurred in about 9 percent of the patients receiving PLENDIL, principally for peripheral edema, headache, or flushing.

Please see the Brief Summary of Prescribing Information on the last page of this advertisement.

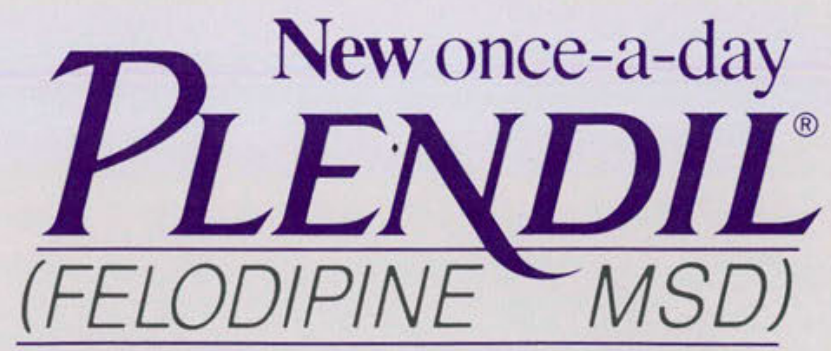

Tablets, $5 \mathrm{mg} 10 \mathrm{mg}$ 


\section{PLENDIL}

(FELODIPINE MSD)

Available in:

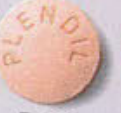

$5 \mathrm{mg}$

$10 \mathrm{mg}$

CONTRAINDICATIONS: PLENDIL is contraindicated in patents who are hypersensitive to this product

PRECAUTIONS: General: Hypotension: Felodipine, like other calcium antagonists, may occasionally precipitate significant hypotension and rarely syncope. It may lead to reflex tachycardia which in susceptible individuals may precipitate angina pectoris. (See ADVERSE REACTIONS.

Heart Failure: Although acute hemodynamic studies in a small number of patients with NYHA Class II or III heart failure treated with felodipine have not demonstrated negative inotropic effects, safety in patients with heart failure has not been established Caution therefore should be exercised when using PLENDIL in patients with heart failure or compromised ventricular function, particularly in combination with a beta blocker.

Elderly Patients or Patients with Impaired Liver Function Patients over 65 years of age or patients with impaired liver function may have elevated plasma concentrations of felodipine and may therefore respond to lower doses of PLENDIL These patients should have their blood pressure monitored closely during dosage adiustment of PLENDIL and should closely during dosage adjustment of PLENDIC and should rarely require doses above $10 \mathrm{mg}$. (See CLINICAL
COLOGY and DOSAGE AND ADMINISTRATION.)

Peripheral Edema: Peripheral edema. generally mild and not associated with generalized fluid retention, was the most common adverse event in the clinical trials. The incidence of peripheral edema was both dose-and age-dependent. Fre quency of peripheral edema ranged from about 10 percent in patients under 50 years of age taking $5 \mathrm{mg}$ daily to about 30 percent in those over 60 years of age taking $20 \mathrm{mg}$ daily. This adverse effect gene

Information for Patients: Patients should be instructed to ake PLENDIL whole and not to crush or chew the tablets They should be told that mild gingival hyperplasia (gum swelling) has been reported. Good dental hygiene de creases its incidence and severity.

NOTE: As with many other drugs, certain advice to patients eing treated with PLENDIL is warranted. This information is intended to aid in the safe and effective use of this medicafion. It is not a disclosure of all possible adverse or intended effects.

Drug Interactions: Beta-Blocking Agents: A pharmacokinetic study of felodipine in conjunction with metoprold demonstrated no significant effects on the pharmacokinetics of felodipine. The AUC and C... of metoprolol. how ever, were increased approximately 31 and 38 percent, respectively. In controlled clinical trials, however, beta-blockers including metoprolol were concurrently administered with felodipine and were well tolerated.

Cimetidine: In healthy subjects pharmacokinetic studies showed an approximately 50 percent increase in the area under the plasma concentration time curve (AUC) as well as the $\mathrm{C}$ - of felodipine when given concomitantly with cimetidine it is anticipated that a clinically significant interaction may occur in some hypertensive patients. Therefore, it is recommended that low doses of PLENDIL be used when given concomitantly with cimetidine.

Digoxin: When given concomitantly with felodipine the peak plasma concentration of digoxin was significantly increased There was, however, no significant change in the AUC thigoxin.

Other Concomitant Therapy: In healthy subjects there were no clinically significant interactions when felodipine was given concomitantly with indomethacin or spironolactone.

Interaction with Food: See CLINICAL PHARMACOLOGY, Pharmacokinetics and Metabolism.

\section{Carcinogenesis, Mutagenesis, Impairment of Fertility:}

a two-year carcinogenicity study in rats fed felodipine at mum recommended human dose on a mg/m² basis). a doserelated increase in the incidence of benign interstitial cell related increase in the testes (Leydig cell tumors) was observed (Leserved in reated ar study in mice at doses up to $138.6 \mathrm{mg} / \mathrm{kg} /$ day $\left(28^{*}\right.$ times the maximum recommended human dose on a mg/m² basis) has been shown to lower testicular testosterone and to produce a corresponding increase in serumluteinizing hormone in rats. The Leydig cell tumor development is possibly secondary to these hormonal effects which have not been observed in man.

In this same rat study a dose-related increase in the incidence of focal squamous cell hyperplasia compared to control was observed in the esophageal groove of male and fernale rats in all dose groups. No other drug-related esophageal or gastric pathology was observed in the rats or with chronic administration in mice and dogs. The latter species. like man, has no anatomical structure comparable to the esophageal groove

Felodipine was not carcinogenic when fed to mice at doses of up to $138.6 \mathrm{mg} / \mathrm{kg} /$ day (28 times ${ }^{*}$ the maximum rec. ommended human dose on a $\mathrm{mg} / \mathrm{m}^{2}$ basis) for per

to 80 weeks in males and 99 weeks in females.

Felodipine did not display any mutagenic activity in vitro in the Ames microbial mutagenicity test or in the mouse lym. phoma forward mutation assay. No clastogenic potential was seen in vivo in the mouse micronucleus test at oral doses up to $2500 \mathrm{mg} / \mathrm{kg}$ ( 506 times" the maximum recommended human dose on a mg/m' basis) or in vitro in a human lympho cyte chromosome aberration assay.

A fertility study in which male and temale rats were ad. ministered doses of 3.8 .9 .6 or $26.9 \mathrm{mg} / \mathrm{kg} /$ day showed no significant effect of felodipine on reproductive performance.

Pregnancy: Pregnancy Category C: Teratogenic Effects Studies in pregnant rabbits administered doses of 0.46 .1 . 2.3 and $4.6 \mathrm{mg} / \mathrm{kg} /$ day (trom 0.4 to 4 times the maximum recommended human dose on a $\mathrm{mg} / \mathrm{m}^{2}$ basis) showed digital anomalies consisting of reduction in size and degree of ossification of the terminal phalanges in the fetuses. The frequency and severity of the changes appeared dose-related and were noted even at the lowest dose. These changes have been shown to occur with other members of the dihy. dropytidine class and ate possibly a result of compromised ar possibly a result of compromised in rats given felodipine.

In a teratology study in cynomolgus monkeys no reduction in the size of the terminal phalanges was observed but an abnormal position of the distal phalanges was noted in about 40 percent of the fetuses.

Nonteratogenic Effects: A prolongation of parturition with difficult labor and an increased frequency of fetal and early postnatal deaths were observed in rats administered doses of $9.6 \mathrm{mg} / \mathrm{kg} /$ day ( 4 times ${ }^{*}$ the maximum human dose on a $\mathrm{ng} / \mathrm{m}^{2}$ basis) and above.

Significant entargement of the mammary glands in excess of the normal enlargement for pregnant rabbits was found with doses greater than or equal to $1.2 \mathrm{mg} / \mathrm{kg} /$ day (equal to the maximum human dose on a $\mathrm{mg} / \mathrm{m}^{2}$ basis). This effect occurred only in pregnant rabbits and regressed during lactation. Similar changes in the mammary glands were ing lactation. Similar changes in the

There are no adequate and well-controlled studies in pregnant women. If felodipine is used during pregnancy, or if the patient becomes pregnant while taking this drug. she should be apprised of the potential hazard to the fetus. possible digital anomalies of the infant, and the potential effects of telodipine on labor and delivery, and on the mammary glands of pregnant females.

Nursing Mothers: it is not known whether this drug is secreted in human milk and because of the potential for serious adverse reactions from felodipine in the infant, a decision should be made whether to discontinue nursing or to discontinue the drug. taking into account the importance of the drug to the mother.

Pediatric Use: Safety and effectiveness in children have not been established.

ADVERSE REACTIONS: In controlled studies in the United States and overseas approximately 3000 patients were treated with felodipine as either the extended-release or the immediate-release formulation

The most common clinical adverse experiences reported with PLENDIL* (Felodipine, MSD) administered as monotherapy in all settings and with all dosage forms of felodipine were peripheral edema and headache. Peripheral edema was generally mild, but it was age- and dose-related and resulted in discontinuation of therapy in about 4 percent of the enrolled patients. Discontinuation of therapy due to any clinical adverse experience occurred in about 9 percent of the patients receiving PLENDIL. principally for peripheral edema headache, or flushing

Adverse experiences that occurred with an incidence ot 1.5 percent or greater during monotherapy with PLENDIL without regard to causality are compared to placebo in the table below.

Percent of Patients with Adverse Effects in Controlled Trials of PLENDIL as Monotherapy (Incidence of discontinuations shown in parentheses)

\begin{tabular}{lrcc}
\hline Adverse Effect & $\begin{array}{c}\text { PLENDIL. \% } \\
\mathbf{N}=\mathbf{7 3 0}\end{array}$ & $\begin{array}{c}\text { Placebo \% } \\
\mathbf{N}=\mathbf{2 8 3}\end{array}$ \\
\hline Peripheral Edema & 22.3 & $(4.2)$ & 3.5 \\
Headache & 18.6 & $(2.1)$ & 10.6 \\
Flushing & 6.4 & $(1.0)$ & 1.1 \\
Dizziness & 5.8 & $(0.8)$ & 3.2 \\
Upper Respiratory Infection & 5.5 & $(0.1)$ & 1.1 \\
Asthenia & 4.7 & $(0.1)$ & 2.8 \\
Cough & 2.9 & $(0.0)$ & 0.4 \\
Paresthesia & $2.5(0.1)$ & 1.8 \\
Dyspepsia & $2.3(0.0)$ & 1.4 \\
Chest Pain & 2.1 & $(0.1)$ & 1.4 \\
Nausea & 1.9 & $(0.8)$ & 1.1 \\
Muscle Cramps & $1.9(0.0)$ & 1.1 \\
Palpitation & $1.8(0.5)$ & 2.5 \\
Abdominal Pain & $1.8(0.3)$ & 1.1 \\
Constipation & 1.6 & $(0.1)$ & 1.1 \\
Diarrhea & 1.6 & $(0.1)$ & 1.1 \\
Pharyngitis & 1.6 & $(0.0)$ & 0.4 \\
Rhinorrhea & 1.6 & $(0.0)$ & 0.0 \\
Back Pain & $1.6(0.0)$ & 1.1 \\
Rash & $1.5(0.1)$ & 1.1 \\
\hline
\end{tabular}

pine, MSD) as monotherapy. the following table describe the incidence

\begin{tabular}{lcccc}
\hline Adverse Effect & $\begin{array}{c}\text { Placebo } \\
\mathbf{N}=121\end{array}$ & $\begin{array}{c}\mathbf{5 . 0} \mathbf{~ m g} \\
\mathbf{N}=\mathbf{7 2}\end{array}$ & $\begin{array}{c}\mathbf{1 0 . 0} \mathbf{m g} \\
\mathbf{N}=\mathbf{1 2 3}\end{array}$ & $\begin{array}{l}\mathbf{2 0} \mathbf{m} \\
\mathbf{N}=\mathbf{5}\end{array}$ \\
\hline Peripheral Edema & 2.5 & 13.9 & 19.5 & 36.0 \\
Palpitation & 0.8 & 0.0 & 2.4 & 12.0 \\
Headache & 12.4 & 11.1 & 18.7 & 28.0 \\
Flushing & 0.0 & 2.8 & 8.1 & 20.0
\end{tabular}

In addition, adverse experiences that occurred in

percent of patients who

Within each category) and serious adverse events that oc

curred at a lower rate or were found during marketing exper ence (those lower rate events are in italics) were: Body as Whole. Facial edema, warm sensation.

Tachycardia, myocardial intarction,

angina pectoris, armythmia, Digestive: knee pain leg pain, toot pain hip pain. gia: Nervous/Psychiatric. Depressior insomnia, irritability, nervousness, so

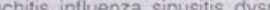
in sneezing: Skin zing: Skin: Contusion. urticaria; Urogenital Decreased irido

Felodipine, as an immediate release formulation also been studied as monotherapy in 680 patients with pertension in U.S. and overseas controlled clinical studies Other adverse experiences not listed above and with an Eatigue; Digestive: Gastrointestinal pain; Musculoskele Arthritis, local weakness, pain: Nervous/Psychiatric: Skin: Hyperhidrosis. pruritus: Sp innitus: Urogenital: Nocturia

Gingival Hyperplasia: Gingival hyperplasia, usually milc ed in $<0.5$ percent of patients in controlled studi This condrion may be avoided or may regress with improve Patients.)

Clinical Laboratory Test Findings: Serum Electrolyte

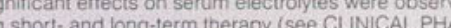
MACOLOGY, Renal/Endocrine Eifects)

Serum Glucose: No significant effects on fasting Serum U.S controlled study.

Liver Enzymes: One of two episodes of elevated serum trans aminases decreased once drug was discontinued

ORDOSAGE: Oral doses of $240 \mathrm{mg} / \mathrm{kg}$ and $264 \mathrm{mg}$ nale and female mice, respectively, and $2390 \mathrm{mg} / \mathrm{kg}$ $2250 \mathrm{mg} / \mathrm{kg}$ in male

$$
\text { a suicide }
$$

ats one patient took

and 20 tablets of nitrazepam. The patient's!

heart rate were normal on admission to hosp

Overdosage might be expected to cause exce bradycardia.

\section{If severe $h$}

should be instituted. The patient should be placed sup with the legs elevated. The administration of intravenous ids may be useful to treat hypotension due to overdosa with calcium antagonists. In case of accompanying brad cardia, atropine (0.5-1 mg) should be administered ithave physician feels they are warranted.

It has not been established whether felodip

\section{DOSAGE AND ADMINISTRATION:}

ecommended the intervals of not less than two weeks. The usual dosage ran is $5.10 \mathrm{mg}$ once daily. The maximum recommended dain an increased blood pressure response but a large in in the rate of peripheral edema and other vasodilaion verse events (see ADVERSE REAC the recommended dosag

\section{PLENDIL should}

Use in the Elderly or Patients with Impaired Liver Functio Patients over 65 years of age or patients with impaired tiver function, because they

monitored closely during dosage adjustme

considered in these patients

\section{MSD

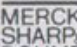

For more detailed information, consult your MSD Representative or see complete Prescribing Informatio Merck Sharp \& Dohme, Division of Merck \& Co, INc., West Point, PA 19486 